\title{
Detection of cancer cells based on glycolytic-regulated surface electrical charges
}

\author{
Wenjun Le ${ }^{1}$, Bingdi Chen ${ }^{1}$, Zheng Cui ${ }^{1,2}$, Zhongmin Liu ${ }^{1 凶}$, Donglu Shi ${ }^{1,3}$ \\ 1 The Institute for Translational Nanomedicine, Shanghai East Hospital, The Institute for Biomedical Engineering \& \\ Nano Science, School of Medicine, Tongji University, Shanghai 200092, China \\ 2 Department of Pathology, School of Medicine, Wake Forest University, Winston-Salem, NC, USA \\ ${ }^{3}$ Department of Mechanical and Materials Engineering, College of Engineering and Applied Science, University of \\ Cincinnati, Cincinnati, OH, USA
}

Received: 29 May 2018 / Accepted: 27 August 2018 / Published online: 1 March 2019

\begin{abstract}
Over the past decades, cell surface charge, although experimentally observed, has not been well understood particularly from the viewpoint of biophysics. Our recent studies have shown that all cancer cells exhibit negative surface charges that are directly proportional to the secreted lactic acid, a unique cancer metabolic characteristic: high rate of glycolysis. We have therefore designed and developed a set of electrically-charged, fluorescent, and super-paramagnetic nanoprobes, capable of sensitive detection of cancer cells based on the surface charges. These probes are utilized to bind onto cells via electrostatic reaction for capture and magnetic separation. In this fashion, we are able to characterize cell surface charges that are regulated by different metabolic patterns, therefore effectively distinguishing the cancer cells from the normal cells. All 22 cancer cells of different organs are found to be negativelycharged therefore bound strongly by the positively-charged nanoprobes, whereas the normal cells show insignificant binding to the nanoprobes of either charge signs (positive or negative). This finding suggests that all tested cancer cells are negatively-charged and normal cells are either charge-neutral or slightly positive. For diagnosis, cancer cells can be detected, electrostatically bound, and magnetically separated in blood by charged and super-paramagnetic nanoprobes. In therapeutics, circulating cancer cells (CTCs) can be filtered and removed in a continuous fashion to reduce the risk of cancer metastasis. If successful, this new nanotechnology will revolutionize early cancer diagnosis and potentially enable new therapeutics in clinical settings.
\end{abstract}

Keywords Nanotechnology, Cancer cell, Cell surface charge, Circulating tumor cells

\section{INTRODUCTION}

Cancer is a serious public health problem in the world (Siegel et al. 2017, 2018). According to the "2014 World Cancer Report" issued by the International Agency for Research on Cancer, the number of new cancer cases worldwide is growing at an alarming rate. In 2012, more than 14 million new cancer cases were reported in

$\triangle$ Correspondence: liu.zhongmin@tongji.edu.cn (Z. Liu), donglu.shi@uc.edu (D. Shi) the world, and it is expected to reach 22 million annually in the next 20 years (Stewart and Wild 2014). At the same time, medical expenditures in the field of cancer are increasing annually. In 2014, the direct medical treatment cost for cancer in the United States was as much as $\$ 87.7$ billion. However, under a huge investment, the cancer mortality rate remains high. A total of 2,712,630 deaths were recorded in the United States in 2015, 22\% of which was from cancer (Siegel et al. 2018). Therefore, investigation of new strategies of cancer diagnosis and therapeutics is urgently needed 
particularly in early cancer diagnosis (Miller et al. 2016).

The electrical surface charges on cancer cells have generated great research interests in recent years, for both understanding of fundamental metabolic mechanisms and clinical diagnostics and therapeutics. The prior studies on cancer cell surface charges involve two major categories of methodology, namely electrophoresis and nanoparticles, but not without some major challenges. On the one hand, the measurement of cell mobility in an electrophoretic field suffers from several critical limitations, such as cumbersomeness of operation, lack of sensitivity, diminished nutrient supply, and only a small percentage of cells being analyzed. On the other hand, the properties of nanoparticles (NPs) carrying a variety of charged molecules maybe altered for the intended non-charge-specific and other specific biochemical reactions. In order to address these problems for more accurate assessment of cell surface charges, we constructed a set of paired, mutually-controlled multifunctional NPs for cancer cell detection and biding under controlled environment that minimizes endocytosis and undesired biochemical reactions. Using this unique set of NPs as basis for a novel methodology, we showed that only the positively-charged NPs electrostatically bind onto a wide array of cancer cells, indiscriminative of the cancer phenotype, but not to the normal cells (control). Furthermore, we found the negative surface charges of cancer cells to be directly regulated by the rate of glycolysis. Based on our findings, we identified a novel cancer cell detection mechanism based on the glycolytic-regulated cancer cell surface charges, which is a fundamental hallmark of cancer cell metabolism.

\section{BACKGROUND OF CELLULAR BIOELECTRICITY}

The field of cellular electrophysiology has a long history. Cell surface charge has been confirmed to be involved in many important cell activity processes, such as the conduction of nerve signals in nerve cells. In these studies, cell surface charge was measured directly by the electrodes in large neurons. It was, however, more difficult to study the electrical properties of smaller somatic cells or a large number of cells. For measuring the surface charges of somatic cells and their differentiated pathogenic cells, cell electrodes are primarily used to determine the potential change at a reference point on the cell surface, but not able to comprehensively assess the overall net cell surface charge state.

In 1780, Galvani studied bioelectricity for the first time. He observed that electric shock caused twitching of frog legs (McLaughlin 1954). Since then, many different methods have been developed to study bioelectrical signal transduction. However, all of these current technologies are inherently limited in accuracy or experimental reliability of cell surface charge, resulting in moderate progress in understanding cell surface charge, as a biophysical phenomenon. For example, the cancer surface charge should be a reflection of a dynamic status underlying complicated metabolic processes. But most previous experiments disregard the dynamic nature of biological cells leading to wrong conclusions on the sign of cancer cell charge, be it negative or positive. There are two main categories of cell surface charge analytical tools. The first type is cell electrophoresis. The major problem with this method is its low sensitivity. The cells need not only a large amount of surface charge but also high voltage in order to move them from point A to B. At the same time, the cells are left for a long time without any necessary energy sources and nutrients resulting in abnormal state that affects the cell status. Furthermore, only a small fraction of cells is being experimentally characterized for charged state, therefore not representative for a typical in vitro situation (large number of cells). Another more recent approach deals with charge tag of macromolecules by nanomaterials. However, in this method, the particle-cell interactions are not entirely electrostatic due to phagocytosis and biochemical effects of cells in foreign bodies. So far, there has not been an effective method that can rule out the interferences from non-charged effects.

The cell surface charge was investigated as early as in the 1930s (Ambrose et al. 1956). The cancerous tissues were found easier to be separated than normal tissues. From 1950s on to 1990s, most studies on cell surface charge were conducted by the electrophoretic mobility of cells (Pestonjamasp and Mehta 1995). However, when cells are placed in an electrophoresis buffer system, they will lose the normal nutrient and energy supply leading to significantly reduced internal metabolic rate of the cells. If the cell surface charge is related to active cell metabolism, the measurement should be time dependent (i.e. the charge status is a dynamic process). In addition, migration movement of cells is also affected by multiple factors such as the friction of the electrophoretic medium and the gravity of the cells. In this case, usually only a very small fraction of the cells can be moved and characterized. This does not accurately reflect the true state of cell surface charge (McLaughlin 1954). Nonetheless, in a few reports, some cancer cells may have negative charges on their surfaces. But there have been major discrepancies among different reports for which a unified conclusion has not been drawn. For 
instance, some of these studies indicate both cancer (Purdom et al. 1958; Vassar et al. 1963) and normal cells (Gogichadze et al. 2014) are negatively-charged. As such, the research communities in bioelectricity studies have not been able to reach an agreeable conclusion on cell surface charge for lacking fundamentals underlying the charge mechanisms. Nonetheless, researchers have long suspected that the surface charges are different between cancer and normal cells. However, due to the measurement limitations described above, the mechanisms responsible for charge behaviors of either type of cells have never been well identified.

\section{NANOTECHNOLOGY DETECTION OF CANCER CELLS VIA GLYCOLYTIC-REGULATED SURFACE CHANGES}

Cancer cells are distinctively characterized by the negatively-charged surfaces due to their unique metabolic processes. There have been extensive studies on the cancer surface biophysical behaviors for both fundamental oncology and clinical diagnosis and treatment. The previous studies on cancer cell surface charges involved measurement of cell mobility in an electrophoretic field. The major limitations of this approach, however, include cumbersomeness of operation, lacking of sensitivity, and inconsistency due to diminished nutrient supply. In particular, in those studies, only a small percentage of cells was analyzed, giving an unrepresentative data for general cell behaviors. Therefore, it has been a key challenge to develop a viable tool that is able to accurately assess the cancer cell surface changes in a reliable fashion.

We have recently developed unique nanoprobes capable of characterizing cell behaviors in a wide range, biochemically and biophysically. However, when the nanoprobes interact with the cells, some critical issues arise on particle active uptake, endocytosis of cells, and non-specific adsorption. In addition, cells may also interact with nanoprobes through biochemical reactions, such as recognition of the modified molecules on the nanoprobes through cell surface receptors (Osaka et al. 2009). Therefore, an accurate assessment of cell surface charge by nanotechnology requires unique design of the probe structures tailored to specific experimental conditions. We have designed and synthesized a multifunctional magnetic nanoprobe based on the following considerations (Chen et al. 2016): (1) how to achieve intimate contact between the nanoparticle and the target cell via electrostatic interactions, and (2) how to minimize the non-specific adsorption between nanoprobes and normal cells. To meet above requirements, we reacted the cells with nanoparticles in an ice bath, that effectively reducing endocytosis and other interferences. Using a magnetic capture technique, we investigated 22 randomly tested cancer cell lines from different species and organs and found all cancer cells to be negatively-charged. Meanwhile, several normal cells were found charge-neutral of slightly positive. This was accomplished by binding cells with magnetic nanoparticles of opposite charges (Fig. 1). The experimental results indicate all positivelycharged nanoparticles massively bind onto cancer cells (negatively-charged) while the normal cells do not respond the charged particles of either signs, indicating they are practically neutral. We also found that the negative surface charge is correlated to glycolysis by directly proportional to the secretion of lactic acid.

The most typical feature of cancer cells is their abnormal glucose metabolism pathway (Chaffer and Weinberg 2011; You and Jones 2012; Warburg 1956). This phenomenon was discovered by Otto Warburg, a German biochemist, as early as 1924 that normal cells depend on the mitochondrial oxidative phosphorylation process to generate the required energy, while cancer cells rely on the glycolytic pathway that subsequently leads to secretion of lactic acid (Hanahan and Weinberg 2011). Adenosine triphosphate (ATP) is used as a substance for storing and transmitting energy in cells, and mainly produced through cytoplasmic glycolysis and mitochondrial oxidative phosphorylation. In normal tissues, $90 \%$ of ATP is derived from oxidative phosphorylation, and only $10 \%$ is derived from aerobic glycolysis. This is known as the Pasteur effect (Fu et al. 2013; Warburg 1924). Compared to normal mature cells, about $80 \%$ of glucose is used in cancer cells to produce ATP in the glycolytic pathway, but not through the oxidative phosphorylation pathway, even under adequate supply. This is known as the Warburg effect (Schell et al. 2014; Copeland and Turner 1980). The highly active glycolysis of cancer cells requires the rapid and large intake of high levels of glucose to generate energy in order to meet the rapid growth requirements. Based on the glucose metabolism of cancer cells that demands more glucose, 18F-fluorodeoxyglucose contrast agent (FDG) is developed to track the position of glucose in the human body, reconstructed by positron emission computed tomography (PET) scanner. The image of FDG in vivo distribution provides a more intuitive way to assess the health status of cancer patients. Currently, this technology has been widely used clinically for diagnosis, staging, and efficacy monitoring of cancer (Hatt et al. 2015; Hutchings et al. 2006).

In addition, cancer cells secrete a large quantity of lactic acid, while normal cells produce carbon dioxide 
A Cell surface Net charges

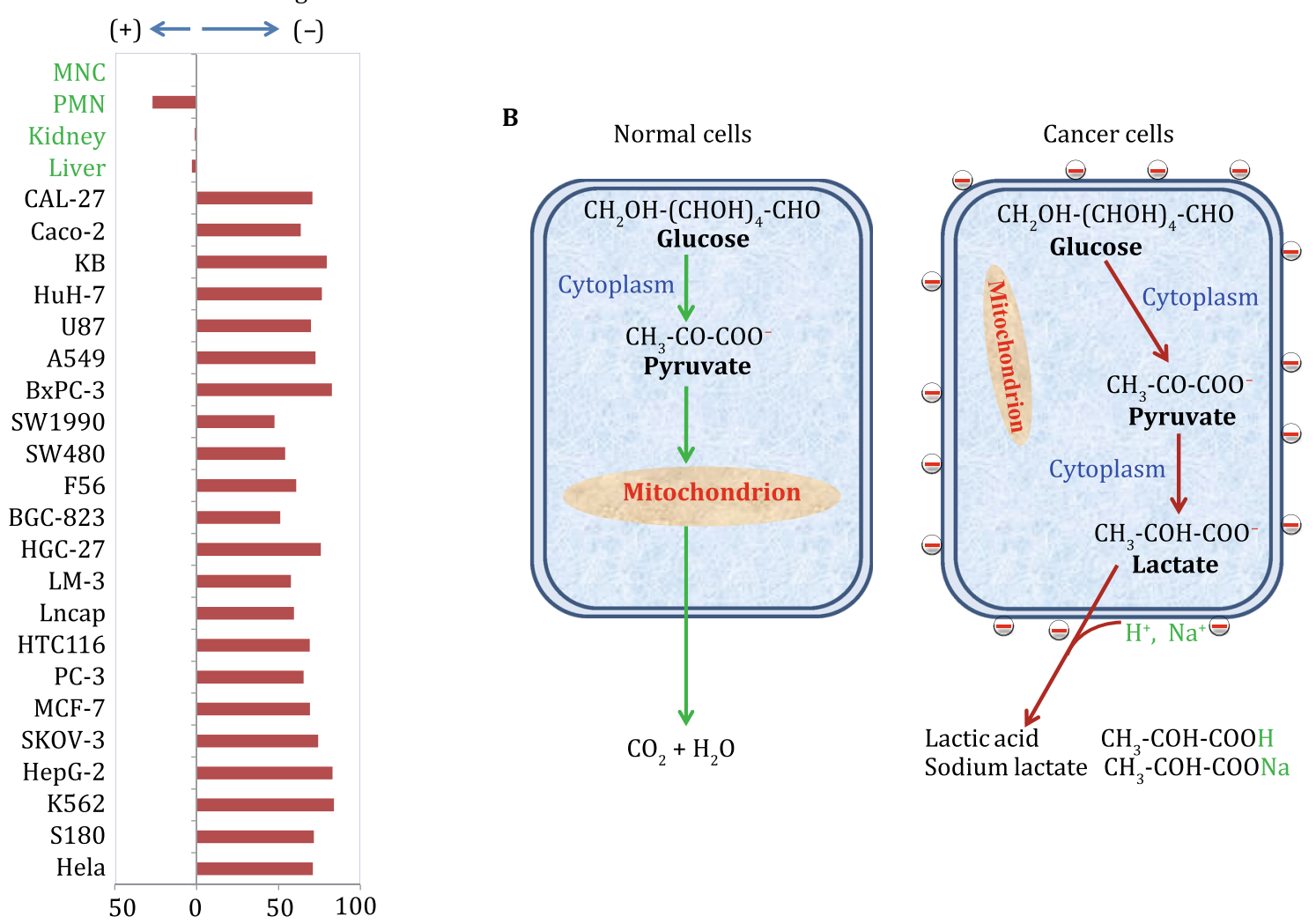

Percentage of cells captured by NPs

Fig. 1 A Net surface charges of cells. The calculated net surface charges expressed in this figure are the net captured percentage of cells by one type charge sign NPs subtracted by the cells captured by the NPs with opposite charge sign as controls. MNC: mononuclear cells; PMN: polymorphonuclear cell or Granulocyte. B Schematic diagram showing secretion of lactate anions leading to a loss of cations from cancer cell surface and leaving behind the negative charges (Chen et al. 2016)

and water (Hsu and Sabatini 2008; Vander Heiden et al. 2009). Several decades ago, Otto Warburg observed that cancer cells ferment glucose in the presence of oxygen, suggesting that defects in mitochondrial respiration may be a potential cause of cancer (Vyas et al. 2016). Highly active glycolysis can not only rapidly meet the energy requirement of cancer cell proliferation for growth, but also produce large amounts of lactic acid, changing the interstitial environment of cancer cells, and facilitating invasion and metastasis of cancer cells (Colegio et al. 2014; Lu et al. 2015). Consequently, a large amount of lactic acid accumulates in the body of the cancer patient (Brand et al. 2016). Almost all known bioelectricity in mammalian cells is generated by the transmembrane movement of mobile ions (Kuismanen and Saraste 1989). Most human cells actively maintain a charge-neutral or slightly positive surface through ion pumps and channels on the plasma membrane. However, almost all metabolically active cancer cells, both in vivo and in vitro, secrete large amounts of lactate ions as mobile anions (Gadsby 2009). This is the result of active glycolysis, in which glucose uptake and lactate secretion can be up to 30 times higher than in normal cells (Hanahan and Weinberg 2011). A large number of cancer cells secrete lactate ions outside the cell across the plasma membrane. When ions pass through the plasma membrane, they will inevitably change the surface charge. Therefore, we conclude that the negative charge on the surface of cancer cells is mainly due to the secretion of lactate across the plasma membrane.

It should be noted that cancer cells may have a slightly elevated surface content of negatively-charged immobilized molecules (e.g., sialic acid), which is $30 \%$ $50 \%$ more than normal cells, but this is hardly comparable to the elevated levels of glycolysis and lactate secretion, that is 30 times higher than normal cell levels (Dubyak 2004; Gadsby et al. 2009). The negative cancer cell surface charge is metabolically regulated by glycolysis, a dynamic process depending on the level of glucose provided.

Therefore, the negative charge generated on the cancer cells is due to different sugar metabolism 
pathways from normal cells. This can explain as to why healthy innate immune granulocytes can distinguish between pathogenic cells and healthy cells. It has been reported that bacteria and some viruses exhibit negative surface charges (Radovic-Moreno et al. 2012; Sonders and Amara 1996). Bacteria without mitochondria can produce energy through glycolysis, whose metabolic properties are similar to those of cancer cells. Therefore, innate immune granulocytes are likely to distinguish healthy cells from the negatively-charged pathogens (Fig. 2).

Since 1999, Cui et al. published a series of research results on natural anti-cancer mice (Blanks et al. 2011; Cui et al. 2003; Cui 2011; Hicks et al. 2006; Riedlinger et al. 2010). The most unexpected finding was that these mice were resistant to cancer because of the completely unexpected granulocytes, immune cells that constantly and rapidly kill cancer cells, instead of natural killer cells or T cells. This result was unexpected for granulocytes to be traditionally known as the bacteria killer. Prior to Cui's works, granulocytes had never been recognized to kill cancer cells so efficiently. Unlike bacteria, the surface of cancer cells has neither lipopolysaccharide (LPS) nor peptidoglycan. How granulocytes efficiently kill cancer cells remained a mystery for a long time. Interestingly, we found granulocytes positivelycharged, capable of targeting and attacking cancer cells via the so-called "immune reaction." However, the biological reactive behavior of granulocytes towards cancer cells has never been explained by electro-active attractions between them due to opposite charges. A picture can be quite straightforwardly depicted based on the charge-driven mechanism. As cancer cells secrete a

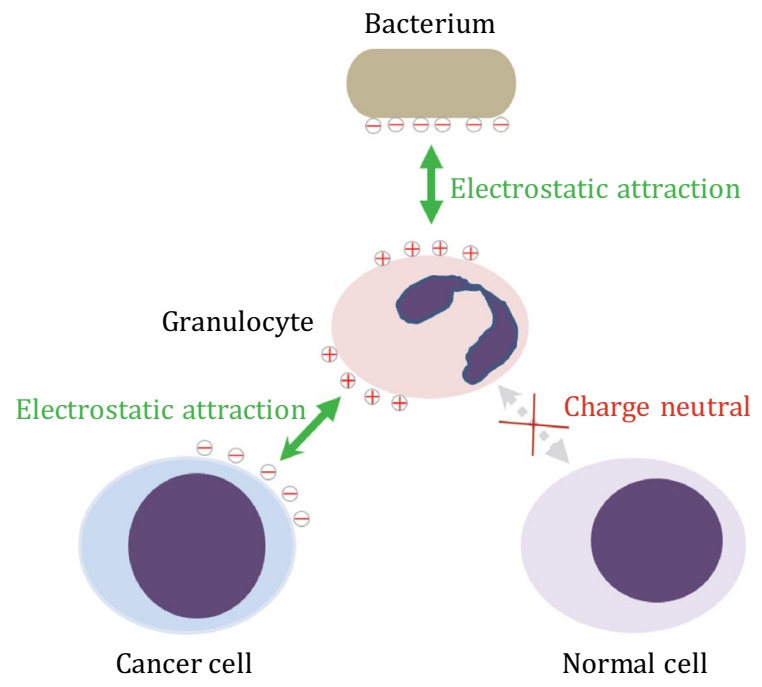

Fig. 2 The hypothesis of granulocyte recognition pathogens large amount of lactic acid in expense of glucose, perpetuating motion of anions results in negatively-charged cell surfaces. Granulocytes, as positively-charged, in the vicinity of the cancer cells would sense the negative electrical charge gradient exhibited by the cancer cell, sustained by the secretion of lactic acid. Due to this electrical potential field, these positive granulocytes are in fact driven by Coulomb force towards the cancer cells for effective killing. This may be regarded as the biophysical interpretation of the "immuno-reaction." The movement of a granulocyte towards a cancer cell has to be driven by a physical potential (or field), that is also associated with a gradient of lactate outwardly from a cancer cell. As both species, namely granulocyte and cancer cell, are oppositely charged, they are attracted towards each other for the intended task of killing. As such we are able to view and interpret the so-called "immune reaction" from a charge field, well explained by the principle of biophysics.

Granulocytes are the most powerful set of defense mechanisms in the human body. People can survive in the long-term state without any $\mathrm{T}$ cell function. For example, patients who have undergone organ transplantation can use drugs to completely suppress Allocell rejection mechanisms and survive for many years. However, the survival period of patients without granulocytes is only a few weeks at most. The cancer cell killing mechanism of granulocytes is a process known as "degranulation." The cytoplasm of granulocytes is filled with granules, which contain a large number of cation peptides, also known as defensins. "Degranulation" is a process in which granulocytes inject cytoplasmic particles of positively-charged polypeptides into target cells through sealed cell surface contact points for target cell killing. It has been hypothesized that if granulocytes contain such a large amount of positively-charged polypeptides, they will be positively-charged on the surface (Lehrer et al. 1993). Therefore, cancer cell targeting by granulocytes is likely associated to their negatively-charged cell membranes (Fig. 2).

The mechanism of pathogen recognition by the innate immune system has not been well explained so far. In an innate immune system, the granulocytes are the major components that can identify many types of pathogenic cells that have completely different surface structures. These pathogenic cells include not only gram-negative bacteria, gram-positive bacteria and fungi, but even hundreds of different types of human cancer cells. Why are active granulocytes able to recognize and distinguish the pathogenic cells from the healthy normal cells? What is ubiquitous on the surface of all these pathogenic cells but not on the normal cells? This puzzling question cannot be easily explained by the 
molecular theories, such as lipopolysaccharides, peptidoglycans and molecular distribution morphology theory. Quite likely, the surface electrical charge differences, regulated by metabolic status of cells, may eventually answer this long-standing question.

\section{DETECTION OF CIRCULATING TUMOR CELLS}

Metastasis is an important indicator of cancer status, which causes most cancer deaths (Chaffer and Weinberg 2011; Yoshii et al. 2016). When cancer cells multiply form malignant tumors, some cancer cells will fall off from the original lesion into the lymph fluid or the blood circulation. These circulating cells in blood stream will be stationed in other tissues and slowly form new lesions. This has been an accepted mechanism of metastasis. Metastasis is mainly transmitted through blood, so circulating tumor cells (CTC) are considered to be the culprit for cancer metastasis (Williams 2013). As early as 1869, Dr. Ashworth first discovered cancer cells from a blood smear of a deceased cancer patient (Ashworth 1869). However, his discovery did not attract people's attention until the mid-1990s only after which people began to realize the potential application of CTC detection (Ghossein et al. 1995; Ghossein and Rosai 1996; Racila et al. 1998). Based on the concept of CTC, personalized treatment is possible as they carry individual genetic information (De Bono et al. 2008; Haber et al. 2011; Yu et al. 2014). CTCs have been found in the blood of many patients with solid tumors. During the transfer process, cells that have fallen off from the lesion can be detected in the blood, especially in the late stage. CTC counts can be used to reflect the characteristics of tumor deterioration to a large extent, therefore a useful strategy in cancer diagnosis and prognosis. Although these cells may be mostly dying of blood circulation due to loss of stroma-derived survival signals or sheer force of blood flow, surviving CTCs are often more lethal and representative. Even a small number of blood samples can be clinically taken and utilized for continuous acquisition of live cancer samples, without causing too much damage to the patient.

However, there have always been technical challenges in the efficient enrichment of live CTCs (Li et al. 2015; Plaks et al. 2013). The detection of CTCs first requires the enrichment of CTCs from blood cells, including red blood cells and white blood cells, which are millions of times larger than CTCs (Fig. 3). The ideal enrichment method is to selectively distinguish cancer cells from normal cells, and it has to apply to all cancer types. None of the previous CTC assays are based on the unique and broad spectrum nature of cancer cells. For example, the principle of a cell filter for trapping CTCs is to pass small blood cells while retaining large cells (Hosokawa et al. 2010; Kim et al. 2016). This method assumes that all cancer cells are larger than normal blood cells, but in fact, cancer cells in some types of cancer (such as non-small cell lung cancer) are smaller than normal cells. In addition, the cell structure has a strong fluidity, whereby the large cells may also pass through the deformation filter. The number of cells captured by this method is usually only a few to a dozen from $7.5 \mathrm{~mL}$ of blood samples, which is likely to seriously underestimate the amount of cancer cells in the blood (Chikaishi et al. 2017; den Toonder 2011; Zink et al. 2004). In addition, the captured CTCs are retained on the filter membrane, therefore difficult to further analyze them.

Dielectrophoresis has also been used to capture CTCs (Moon et al. 2011). The mechanism of this method is based on the fact that cancer cells have different dielectric properties, thereby increasing cell surface folds and surface areas. However, cell surface folds are not unique properties of cancer cells, making it not exclusive in distinguishing between cancer and normal cells. Another strategy for capturing CTCs is to use antibodies that recognize cell surface proteins (Nagrath et al. 2007; Yoon et al. 2013; Yu et al. 2013). For example, using the epithelial cell adhesion molecule EpCAM as a biomarker has been extremely popular in cell targeting. The basic principle assumes a cell to be a cancerous epithelial cancer cell if EpCAM is found absent on its surface. There are three fundamental shortcomings of this method: (1) many circulating epithelial cancer cells have achieved epithelialmesenchymal transition (EMT) and thus lost expression of EpACM (Gorges et al. 2012); (2) cancer cells of mesenchymal origin, for example, sarcoma and neuroblastoma cells do not express EpCAM (Tellez-Gabriel et al. 2016); and (3) some epithelial cancer cells also lose EpCAM expression during conversion to cancer stem cells (Pore et al. 2016). Therefore, using EpCAM antibodies to capture CTCs can seriously underestimate the real amount of cancer cells in blood.

In summary, the major concern about current CTC capture methods is that the characteristic of the cells selected is not unique to cancer cells in detection of CTCs. This is the main obstacle for these methods to be clinically accepted and applied. Meanwhile, it has been difficult to identify a quantitatively detectable parameter that is a hallmark characteristic shared by all cancer cells regardless phenotypical and molecular differences. But in our recent research, we have found glycolyticregulated cell surface charges unique to cancer cells. This negative surface change is a biophysical 
Fig. 3 Hurdles and solutions in CTC research. Biophysical factors that may diminish the detection of CTCs include filtration of large CTCs in smaller capillaries (A), clustering of tumor cells that lodge in capillaries (B), and cloaking of CTCs by platelets or coagulation factors (C). Biological factors that likely complicate the detection and isolation of clinically relevant populations of CTCs that currently rely on epithelial markers include: the presence of benign circulating epithelial cells (D), the large heterogeneity among CTCs (E), the possible stemness of a subpopulation of CTCs (F), the (partial) epithelialmesenchymal transition (EMT) that some CTCs undergo during dissemination (G), and the unclear seeding potential of detected CTCs (H). Future research needs to be focused on improving detection and isolation of CTCs (I), and single-cell "omics." (J) (Plaks et al. 2013)

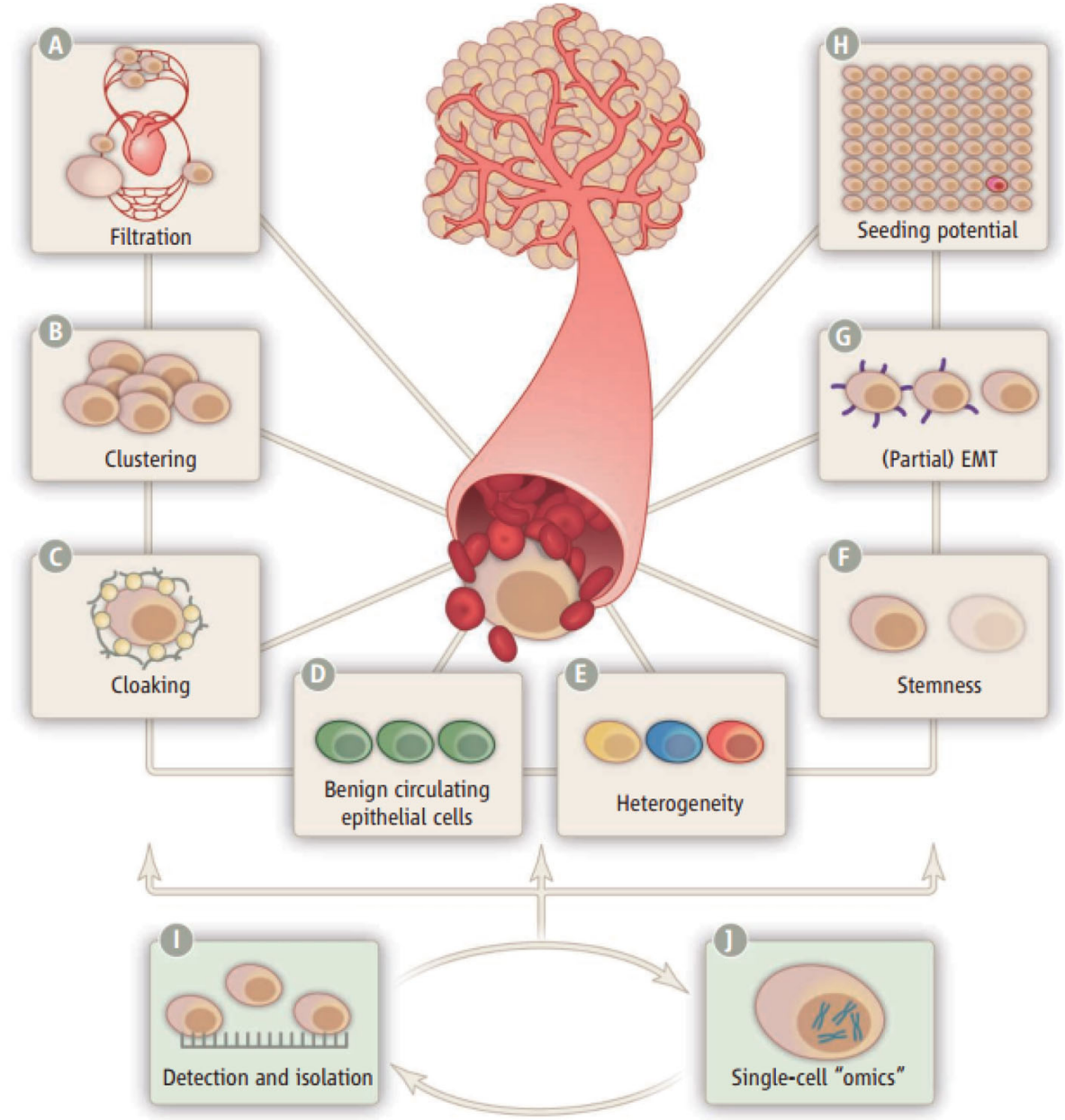

manifestation of the Warburg effect, directly connected to the active glycolytic pathway that is completely different from normal cells. Secretion of a large amount of lactic acid proportionally generates a large negative charge on the surface of cancer cells, that is measureable and detectable by nano means. With this unique commonality of cancer cells, we have developed a new CTC detection nanotechnology based on surfacecharged, fluorescent, and super-paramagnetic nanoparticles. Preliminary clinical data show that, in the circulating blood of cancer patients, this CTC technology can capture a large number of negatively-charged cancer cells, presumably the CTCs upon further analysis. This new technique is markerless but solely based on the biophysical properties of cancer cells, capable of universally and sensitively capturing and detecting of various cancer cells. This novel approach will show promise in early cancer diagnosis, prognosis, and therapeutics.

\section{SUMMARY AND PERSPECTIVES}

The charge-based cancer detection strategy will revolutionize the current CTC technology, so profoundly important to cancer management, diagnosis and therapy. The discovery of cancer surface charge will also provide vital information for the fundamental study of cancer metabolism making significant contribution to cancer biology and oncology. Based on this concept, one is able to detect CTCs from a small quantity of blood sample $(1 \mathrm{~mL})$ in a straightforward and timely fashion. This will highly simplify the current cancer diagnostic methods that rely on complicated and expensive methods from marker and molecules levels.

Acknowledgement This study was supported by National Natural Science Foundation of China (31671029, 81772285), Shanghai Natural Science Foundation (16ZR1400700), National Postdoctoral Program for Innovation Talents (BX201700173), and China Postdoctoral Science Foundation (2017M621534). 


\section{Compliance with Ethical Standards}

Conflict of interest Wenjun Le, Bingdi Chen, Zheng Cui, Zhongmin Liu and Donglu Shi declare that they have no conflict of interest.

Human and animal rights and informed consent This article does not contain any studies with human or animal subjects performed by any of the authors.

Open Access This article is distributed under the terms of the Creative Commons Attribution 4.0 International License (http:// creativecommons.org/licenses/by/4.0/), which permits unrestricted use, distribution, and reproduction in any medium, provided you give appropriate credit to the original author(s) and the source, provide a link to the Creative Commons license, and indicate if changes were made.

\section{References}

Ambrose EJ, James AM, Lowick JHB (1956) Differences between the electrical charge carried by normal and homologous tumour cells. Nature 177(4508):576

Ashworth TR (1869) A case of cancer in which cells similar to those in the tumours were seen in the blood after death. Aust Med J 14:146

Blanks MJ, Stehle JR, Du W, Adams JM, Willingham MC, Allen GO, $\mathrm{Hu} J$ J, Lovato J, Molnar I, Cui Z (2011) Novel innate cancer killing activity in humans. Cancer Cell Int 11(1):26

Brand A, Singer K, Koehl GE, Kolitzus M, Schoenhammer G, Thiel A, Matos C, Bruss C, Klobuch S, Peter K, Kastenberger M, Bogdan C, Schleicher U, Mackensen A, Ullrich E, Fichtner-Feigl S, Kesselring R, Mack M, Ritter U, Schmid M, Blank C, Dettmer K, Oefner PJ, Hoffmann P, Walenta S, Geissler EK, Pouyssegur J, Villunger A, Steven A, Seliger B, Schreml S, Haferkamp S, Kohl E, Karrer S, Berneburg M, Herr W, Mueller-Klieser W, Renner K, Kreutz M (2016) LDHA-associated lactic acid production blunts tumor immunosurveillance by $\mathrm{T}$ and NK cells. Cell Metab 24(5):657-671

Chaffer CL, Weinberg RA (2011) A perspective on cancer cell metastasis. Science 331(6024):1559-1564

Chen B, Le W, Wang Y, Li Z, Wang D, Ren L, Lin L, Cui S, Hun JJ, Hu Y, Yang P, Ewing RC, Shi DL, Cui Z (2016) Targeting negative surface charges of cancer cells by multifunctional nanoprobes. Theranostics 6(11):1887

Chikaishi Y, Yoneda K, Ohnaga T, Tanaka F (2017) EpCAMindependent capture of circulating tumor cells with a 'universal CTC-chip'. Oncol Rep 37(1):77-82

Colegio OR, Chu NQ Szabo AL, Chu T, Rhebergen AM, Jairam V, Cyrus N, Brokowski CE, Eisenbarth SC, Phillips GM, Cline GW, Phillips AJ, Medzhitov R (2014) Functional polarization of tumour-associated macrophages by tumour-derived lactic acid. Nature 513(7519):559

Copeland L, Turner JF (1980) The regulation of glycolysis and the pentose phosphate pathway. In: Davies DD (ed) Metabolism and respiration. Academic Press, New York, pp 279-316

Cui Z (2011) Granular cell anticancer therapy. Tsinghua University Press, Beijing

Cui Z, Willingham MC, Hicks AM, Alexander-Miller MA, Howard TD, Hawkins GA, Miller MS, Weir HM, Du W, DeLong CJ (2003) Spontaneous regression of advanced cancer: identification of a unique genetically determined, age-dependent trait in mice. Proc Natl Acad Sci USA 100(11):6682-6687
De Bono JS, Scher HI, Montgomery RB, Parker C, Miller MC, Tissing H, Doyle GV, Terstappen LW, Pienta KJ, Raghavan D (2008) Circulating tumor cells predict survival benefit from treatment in metastatic castration-resistant prostate cancer. Clin Cancer Res 14(19):6302-6309

den Toonder J (2011) Circulating tumor cells: the grand challenge. Lab Chip 11(3):375-377

Dubyak GR (2004) Ion homeostasis, channels, and transporters: an update on cellular mechanisms. Adv Physiol Educ 28(4):143-154

Fu D, Mitra K, Sengupta P, Jarnik M, Lippincott-Schwartz J, Arias IM (2013) Coordinated elevation of mitochondrial oxidative phosphorylation and autophagy help drive hepatocyte polarization. Proc Natl Acad Sci USA 110(18):7288-7293

Gadsby DC (2009) Ion channels versus ion pumps: the principal difference, in principle. Nat Rev Mol Cell Biol 10(5):344

Gadsby DC, Takeuchi A, Artigas P, Reyes N (2009) Peering into an ATPase ion pump with single-channel recordings. Philos Trans R Soc B 364(1514):229-238

Ghossein RA, Rosai J (1996) Polymerase chain reaction in the detection of micrometastases and circulating tumor cells. Cancer 78(1):10-16

Ghossein RA, Scher HI, Gerald WL, Kelly WK, Curley T, Amsterdam A, Zhang ZF, Rosai J (1995) Detection of circulating tumor cells in patients with localized and metastatic prostatic carcinoma: clinical implications. J Clin Oncol 13(5):1195-1200

Gogichadze G, Gogichadze T, Misabishvili E, Kamkamidze G (2014) Possible effect of variable membrane potential of a cancer cell on different carcinogenic processes. Georgian Med News 234:116-120

Gorges TM, Tinhofer I, Drosch M, Röse L, Zollner M, Krahn T, von Ahsen $O$ (2012) Circulating tumour cells escape from EpCAMbased detection due to epithelial-to-mesenchymal transition. BMC Cancer 12(1):178

Haber DA, Gray NS, Baselga J (2011) The evolving war on cancer. Cell 145(1):19-24

Hanahan D, Weinberg RA (2011) Hallmarks of cancer: the next generation. Cell 144(5):646-674

Hatt M, Majdoub M, Vallières M, Tixier F, Le Rest CC, Groheux D, Hindié E, Martineau A, Pradier 0 , Hustinx R, Perdrisot R, Guillevin R, Naqa IE, Visvikis D (2015) 18F-FDG PET uptake characterization through texture analysis: investigating the complementary nature of heterogeneity and functional tumor volume in a multi-cancer site patient cohort. J Nucl Med 56(1):38-44

Hicks AM, Riedlinger G, Willingham MC, Alexander-Miller MA, Von Kap-Herr C, Pettenati MJ, Sanders AM, Weir HM, Du W, Kim J, Simpson AJ, Old LJ, Cui Z (2006) Transferable anticancer innate immunity in spontaneous regression/complete resistance mice. Proc Natl Acad Sci USA 103(20):7753-7758

Hosokawa M, Hayata T, Fukuda Y, Arakaki A, Yoshino T, Tanaka T, Matsunaga T (2010) Size-selective microcavity array for rapid and efficient detection of circulating tumor cells. Anal Chem 82(15):6629-6635

Hsu PP, Sabatini DM (2008) Cancer cell metabolism: Warburg and beyond. Cell 134(5):703-707

Hutchings M, Loft A, Hansen M, Pedersen LM, Buhl T, Jurlander J, Buus S, Keiding S, D'Amore F, Boesen A, Berthelsen AK, Lena Specht (2006) FDG-PET after two cycles of chemotherapy predicts treatment failure and progression-free survival in Hodgkin lymphoma. Blood 107(1):52-59

Kim TH, Lim M, Park J, Oh JM, Kim H, Jeong H, Lee SJ, Park HC, Jung S, Kim BC, Lee K, Kim MH, Park DY, Kim GH, Cho YK (2016) FAST: size-selective, clog-free isolation of rare cancer cells 
from whole blood at a liquid-liquid interface. Anal Chem 89(2):1155-1162

Kuismanen E, Saraste J (1989) Low temperature-induced transport blocks as tools to manipulate membrane traffic. Methods Cell Biol 3:257-274

Lehrer RI, Lichtenstein AK, Ganz T (1993) Defensins: antimicrobial and cytotoxic peptides of mammalian cells. Annu Rev Immunol 11(1):105-128

Li P, Mao Z, Peng Z, Zhou L, Chen Y, Huang PH, Truica CI, Drabick JJ, El-Deiry WS, Dao M, Suresh S, Huang TJ (2015) Acoustic separation of circulating tumor cells. Proc Natl Acad Sci USA 112(16):4970-4975

Lu J, Tan M, Cai Q (2015) The Warburg effect in tumor progression: mitochondrial oxidative metabolism as an antimetastasis mechanism. Cancer Lett 356(2):156-164

McLaughlin PJ (1954) A history of the theories of aether and electricity. Philos Stud 4:118-119

Miller KD, Siegel RL, Lin CC, Mariotto AB, Kramer JL, Rowland JH, Stein KD, Alteri R, Jemal A (2016) Cancer treatment and survivorship statistics. CA: A Cancer J Clin 66(4):271-289

Moon HS, Kwon K, Kim SI, Han H, Sohn J, Lee S, Jung HI (2011) Continuous separation of breast cancer cells from blood samples using multi-orifice flow fractionation (MOFF) and dielectrophoresis (DEP). Lab Chip 11(6):1118-1125

Nagrath S, Sequist LV, Maheswaran S, Bell DW, Irimia D, Ulkus L, Simth MR, Kwak EL, Diagumarthy S, Muzikansky A, Ryan P, Balis UJ, Tompkin RG, Haber DA, Toner M (2007) Isolation of rare circulating tumour cells in cancer patients by microchip technology. Nature 450(7173):1235

Osaka T, Nakanishi T, Shanmugam S, Takahama S, Zhang H (2009) Effect of surface charge of magnetite nanoparticles on their internalization into breast cancer and umbilical vein endothelial cells. Colloids Surf, B 71(2):325-330

Pestonjamasp VK, Mehta NG (1995) Erythrocytes from Yoshida ascites sarcoma-bearing rats have reduced surface charge: the effect of tumor products. Cancer Biochem Biophys 15(1):19-23

Plaks V, Koopman CD, Werb Z (2013) Circulating tumor cells. Science 341(6151):1186-1188

Pore M, Meijer C, de Bock GH, Boersma-van Ek W, Terstappen LW, Groen HJ, Timens W, Kruyt FAE, Hiltermann TJN (2016) Cancer stem cells, epithelial to mesenchymal markers, and circulating tumor cells in small cell lung cancer. Clin Lung Cancer 17(6):535-542

Purdom L, Ambrose EJ, Klein G (1958) A correlation between electrical surface charge and some biological characteristics during the stepwise progression of a mouse sarcoma. Nature 181(4623):1586

Racila E, Euhus D, Weiss AJ, Rao C, McConnell J, Terstappen LW, Uhr JW (1998) Detection and characterization of carcinoma cells in the blood. Proc Natl Acad Sci USA 95(8):4589-4594

Radovic-Moreno AF, Lu TK, Puscasu VA, Yoon CJ, Langer R, Farokhzad OC (2012) Surface charge-switching polymeric nanoparticles for bacterial cell wall-targeted delivery of antibiotics. ACS Nano 6(5):4279-4287
Riedlinger G, Adams J, Stehle JR, Blanks MJ, Sanders AM, Hicks AM, Willingham MC, Cui Z (2010) The spectrum of resistance in SR/CR mice: the critical role of chemoattraction in the cancer/leukocyte interaction. BMC Cancer 10(1):179

Schell JC, Olson KA, Jiang L, Hawkins AJ, Van Vranken JG, Xie J, Egnatchik RA, DeBeradinis RJ, Rutter J (2014) A role for the mitochondrial pyruvate carrier as a repressor of the Warburg effect and colon cancer cell growth. Mol Cell 56(3):400-413

Siegel RL, Miller KD, Jemal A (2017) Cancer statistics, 2017. CA: A Cancer J Clin 67:7-30

Siegel RL, Miller KD, Jemal A (2018) Cancer statistics, 2008. Ca: A Cancer J Clin 68:5-29

Sonders MS, Amara SG (1996) Channels in transporters. Curr Opin Neurobiol 6(3):294-302

Stewart B, Wild CP (2014) World cancer report 2014

Tellez-Gabriel M, Brown HK, Young R, Heymann MF, Heymann D (2016) The challenges of detecting circulating tumor cells in sarcoma. Front Oncol 6:202

Vander Heiden MG, Cantley LC, Thompson CB (2009) Understanding the Warburg effect: the metabolic requirements of cell proliferation. Science 324(5930):1029-1033

Vassar PS (1963) Electrophoretic mobility of human tumour cells. Nature 197(4873):1215-1216

Vyas S, Zaganjor E, Haigis MC (2016) Mitochondria and cancer. Cell 166(3):555-566

Warburg 0 (1924) Über den stoffwechsel der carcinomzelle. Naturwissenschaften 12(50):1131-1137

Warburg $O$ (1956) On the origin of cancer cells. Science 123(3191):309-314

Yoon HJ, Kim TH, Zhang Z, Azizi E, Pham TM, Paoletti C, Lin J, Ramnath N, Wicha MS, Hayes DF, Simeone DM, Nagrath S (2013) Sensitive capture of circulating tumour cells by functionalized graphene oxide nanosheets. Nat Nanotechnol 8(10):735

Yoshii T, Geng Y, Peyton S, Mercurio AM, Rotello VM (2016) Biochemical and biomechanical drivers of cancer cell metastasis, drug response and nanomedicine. Drug Discov Today 21(9):1489-1494

You JS, Jones PA (2012) Cancer genetics and epigenetics: two sides of the same coin? Cancer Cell 22(1):9-20

Yu M, Bardia A, Wittner BS, Stott SL, Smas ME, Concannon KF (2013) Circulating breast tumor cells exhibit dynamic changes in epithelial and mesenchymal composition. Science 339:580-584

Yu M, Bardia A, Aceto N, Bersani F, Madden MW, Donaldson MC, Desai R, Zhu H, Comaills V, Zheng Z, Wittner BS, Petar Stojanov, Brachtel E, Sgroi D, Kapur R, Shioda T, Ting DT, Ramaswamy S, Getz G, Iafrate AJ, Benes C, Toner M, Maheswaran S, Harber D (2014) Ex vivo culture of circulating breast tumor cells for individualized testing of drug susceptibility. Science 345(6193):216-220

Zink D, Fischer AH, Nickerson JA (2004) Nuclear structure in cancer cells. Nat Rev Cancer 4(9):677

Williams SCP (2013) Circulating tumor cells. Proc Natl Acad Sci USA 110(13):4861-4861 